\title{
PENERAPAN ZOOM DAN GOOGLE CLASSROOM DALAM PELATIHAN MAPLE CALCULATOR DI SMP NEGERI 1 TERAS
}

\author{
Alfi Maulani' ${ }^{1)}$, Sri Supanti Nur Hayati' ${ }^{2)}$, Asih Surati ${ }^{3)}$ \\ ${ }^{1}$ Program Studi Matematika, Fakultas MIPA, Universitas Pamulang \\ ${ }^{2,3}$ SMP Negeri 1 Teras
}

\begin{abstract}
Abstrak
Software matematika dapat membantu siswa/i dalam mengaplikasikan simbol, grafik serta menyelesaikan perhitungan matematika secara tepat dan teliti. Kenyataannya, siswa/i masih banyak menghitung secara manual dalam menyelesaikan persoalan matematika, padahal sudah banyak software matematika yang bisa diaplikasikan dalam menyelesaian persoalan matematika secara akurat, cepat dan tepat. Oleh sebab itu diadakan pengabdian masyarakat berupa pelatihan software Maple Calculator pada mata pelajaran matematika pada siswa/i tingkat SMP khususnya siswa/i kelas IX di SMP NEGERI 1 TERAS. SMP NEGERI 1 TERAS merupakan salah satu sekolah yang telah memanfaatkan e-learning sebagai media pembelajaran selama masa pandemi Covid-19 (Oktober - Desember 2020). Kegiatan pembelajaran menggunakan media e-learning di sekolah tersebut memanfaatkan aplikasi Zoom dan Google Classroom (e-learning). Oleh sebab itu pelaksanaan pengabdian masyarakat dilakukan secara daring menggunakan aplikasi yang sama. Kegiatan pengabdian masyarakat secara umum berhasil memberikan pengetahuan dalam informasi penggunaan software Maple Calculator serta prosedur di dalamnya melalui 10 contoh soal dan pembahasan operasi dan faktorisasi bentuk aljabar dan pencarian Grafik 2D dan 3D dari persamaan tersebut.
\end{abstract}

Kata Kunci: Matematika, software, maple, pelatihan, classroom.

\begin{abstract}
Mathematical software can help students apply symbols, graphs, and complete mathematical calculations accurately and accurately. Students still count a lot manually in solving mathematical problems, even though there is much mathematical software that can be applied in solving mathematical problems accurately, quickly, and precisely. Therefore, community service is held in the form of Maple Calculator software training in mathematics in junior high school students, especially grade IX students at Junior High School 1 TERAS. Junior High School 1 TERAS is one of the schools that has used e-learning as a learning medium during the Covid-19 pandemic (October - December 2020). Learning activities using elearning media at the school utilizing the Zoom and Google Classroom (e-learning) application. Therefore the implementation of community service is carried out online using the same application. Community service activities, in general, succeeded in providing knowledge in information on the use of Maple Calculator software and procedures in it through 10 examples of the operation and factorization of algrebaic expressions problems and solves and the search for $2 D$ and $3 D$ Graphics from the equation.
\end{abstract}

Keywords: Mathematics, software, maple calculator, training, classroom.

\footnotetext{
Correspondence author: 1) Alfi Maulani,dosen02330@unpam.ac.id, Tangerang Selatan, Indonesia

2) Sri Supanti Nur Hayati, nurpanti@gmail.com, Boyolali, Indonesia

3) Asih Surati, asihsurati1@ gmail.com, Boyolali, Indonesia
} 


\section{PENDAHULUAN}

Zoom dan Google Classroom menjadi salah satu platform pembelajaran di dunia pendidikan saat ini yang dikembangkan dengan tujuan agar lembaga-lembaga pendidikan beralih menuju sistem pembelajaran, penugasan, maupun penilaian tanpa kertas (Google, 2017). Zoom dan Google Classroom (e-learning) juga melibatkan banyak layanan Google secara bersamaan. Zoom dan Google Classroom dapat diakses melalui komputer pribadi dan smartphone. Fitur pembelajaran pada Google Classroom (e-learning) yang dapat digunakan oleh guru dalam proses pembelajaran online antara lain membuat pengumuman (create announcement), membuat penugasan (create assignment), membuat pertanyaan (create question), serta menyalin aktivitas yang pernah dilaksanakan sebelumnya (reuse post). Kelebihan Zoom dan Google Classroom yakni elearning ini mudah dipelajari penggunaannya oleh guru maupun siswa. Dengan bantuan Zoom dan (e-learning) Google Classroom, guru dapat mengkreasikan kelas virtualnya sendiri untuk melaksanakan pembelajaran online dan mengunggah bahan instruksional yang di dalamnya terdapat sumber belajar untuk dipelajari siswa secara mandiri saat di rumah.

Siswa dan siswi sering mengalami kesulitan dalam menguasai ilmu matematika. Rata-rata nilai PTS dan PAS yang hampir selalu rendah untuk bidang studi matematika menjadi indikator sulitnya matematika dikalangan para siswa. Para guru melakukan usaha kreatif untuk membuat para siswa-siswi tertarik untuk mempelajari matematika (Nurina, 2014). Guru di tuntut untuk melakukan usaha kreatif untuk membuat matematika yang abstrak menjadi lebih realistik oleh para siswa-siswi (Munandar, 2014). Seiring berkembangnya zaman teknologi semakin maju. Software yang digunakan dalam memudahan belajar Matematika salah satunya adalah Maple Calculator.

Anak didik yang hanya diberikan model pengajaran konvensional, dimana guru berdiri di depan kelas kemudian menerangkan tentang mata pelajaran, itu dirasakan masih terdapat kekurangan. Bagi anak didik yang memperhatikan, itu tidak menjadi masalah. Tapi bila ada anak didik yang karena sesuatu hal tidak bisa mengikuti pelajaran, maka anak didik tersebut akan ketinggalan untuk mendapatkan pengetahuan yang seharusnya dia dapat.

Oleh karena itu, dibutuhkan metode pembelajaran yang dapat mengakomodasi hal tersebut, dalam hal ini adalah software Maple Calculator. Sebelumnya (Suhandri \& Senada, 2016) telah menggunakan pembelajaran berbantuan software Maple sebagai media dalam meningkatkan prestasi belajar mahasiswa di Riau. (Saparwadi \& Yuwono, 2019) telah menggunakan software Maple sebagai media dalam menganalisis hasil kerja mahasiswa di Malang. Pada penelitian ini, software Maple Calculator diterapkan sebagai media pembelajaran matematika bagi siswa SMP NEGERI 1 TERAS di Boyolali.

\section{METODE PELAKSANAAN} berikut. :

Metode yang diterapkan dalam melakukan pengabdian ini diantaranya sebagai

1). Pengadaan evaluasi awal berupa pre-test kepada siswa-siswa terkait materi operasi dan faktorisasi bentuk aljabar serta menggambar grafik persamaan tersebut.

2). Pengenalan pembelajaran dengan menggunakan google classroom. 
3). Pengenalan pembelajaran dengan menggunakan software matematika Maple Calculator.

4). Pelatihan penggunaan software matematika Maple Calculator.

5). Pengadaan evaluasi akhir berupa post-test.

Kepakaran yang dibutuhkan dalam pengabdian ini adalah matematika dan teknologi informatika. Berikut adalah kepakaran tim dan tugasnya masing-masing:

1). Ketua Pengusul. Kepakaran: Ahli pada bidang matematika dan teknologi informatika. Sehingga memudahkan dalam pelaksanaan Pengabdian. Kepakaran ini dibutuhkan mitra terkait karena sesuai dengan yang akan diterapkan di lapangan yaitu pengenalan pembelajaran dengan menggunakan software matematika Maple Calculator. Tugas:

a. Bertanggung jawab atas kegiatan pengabdian ini.

b. Berkoordinasi dengan mitra dan anggota pengusul.

c. Memberikan pelatihan software matematika secara langsung.

d. Membuat laporan kegiatan.

e. Membuat dokumentasi berupa foto dan video.

f. Membuat karya ilmiah untuk jurnal.

2). Anggota Pengusul. Kepakaran: Ahli pada bidang matematika, yang mampu dan memahami seputar pengajaran bidang matematika. Kepakaran ini dibutuhkan mitra terkait karena sesuai dengan yang akan diterapkan di lapangan yaitu pengadaan evaluasi awal dan akhir materi operasi dan faktorisasi bentuk aljabar serta menggambar grafik persamaan tersebut.

3). Anggota Pengusul. Kepakaran: Ahli pada bidang informatika, yang mampu dan memahami seputar pengajaran bidang teknologi informatika. Kepakaran ini dibutuhkan mitra terkait karena sesuai dengan yang akan diterapkan di lapangan yaitu pelatihan penggunaan software matematika Maple Calculator.

\section{HASIL DAN PEMBAHASAN}

Hasil penelitian yang difokuskan terhadap 28 peserta (jumlah standar siswa/i dalam satu kelas) di salah satu SMP di kota Boyolali menunjukkan keberhasilan pencapaian kegiatan pengabdian masyarakat ini yang dapat dilihat pada Tabel 1. Poin standar keberhasilan yang pertama adalah target prosentase keaktifan peserta dalam memahami materi dan menjawab soal-soal pelatihan PKM. Prosentase keaktifan peserta dalam memahami materi dan menjawab soal-soal pelatihan PKM sebesar 100\% melebihi target yang sudah direncanakan sebelumnya sebesar $85 \%$. Poin standar keberhasilan yang kedua adalah rata-rata nilai peserta dalam memahami materi dan menjawab soal-soal pelatihan PKM. Rata-rata nilai peserta dalam memahami materi dan menjawab soal-soal pelatihan PKM adalah 88,98 melebihi target yang sudah direncanakan sebelumnya yaitu 80 . Berdasarkan hasil kuesioner, poin standar keberhasilan yang ketiga yaitu pemahaman dan praktek materi yang diselenggarakan dengan cara ceramah online dapat dimengerti dengan sangat baik oleh siswa. 
Tabel 1 Pencapaian Kegiatan PKM

\begin{tabular}{|l|l|l|}
\hline Poin Standar Keberhasilan & Hasil & Target \\
\hline Prosentase Keaktifan & $100 \%$ & $85 \%$ \\
\hline Rata-rata Nilai & 88,98 & 85 \\
\hline Kuesioner & Respon Sangat Baik & Respon Baik \\
\hline
\end{tabular}

Sebelum kegiatan pelatihan dapat dilaksanakan, baik peserta pelatihan maupun Tim PKM perlu menginstall aplikasi Zoom dan Google Classroom melalui Playstore atau Google Chrome. Sementara itu pihak Sekolah SMP NEGERI 1 TERAS yang diwakili oleh Ibu Asih Surati, S.Ag., membuat kelas maya menggunakan Zoom dan Google Classroom untuk pelaksanaan acara PKM dengan nama, "PKM Unpam - SMP NEGERI 1 TERAS". Setelah kelas maya dibuat, Tim PKM diundang untuk join kelas. Gambar 1 memperlihatkan daftar Panitia Pelaksana Kegiatan Zoom dan Google Classroom, yakni perpaduan Dosen pelaksana PKM, Guru dan Perwakilan Siswa/i Kelas IX SMP NEGERI 1 TERAS.

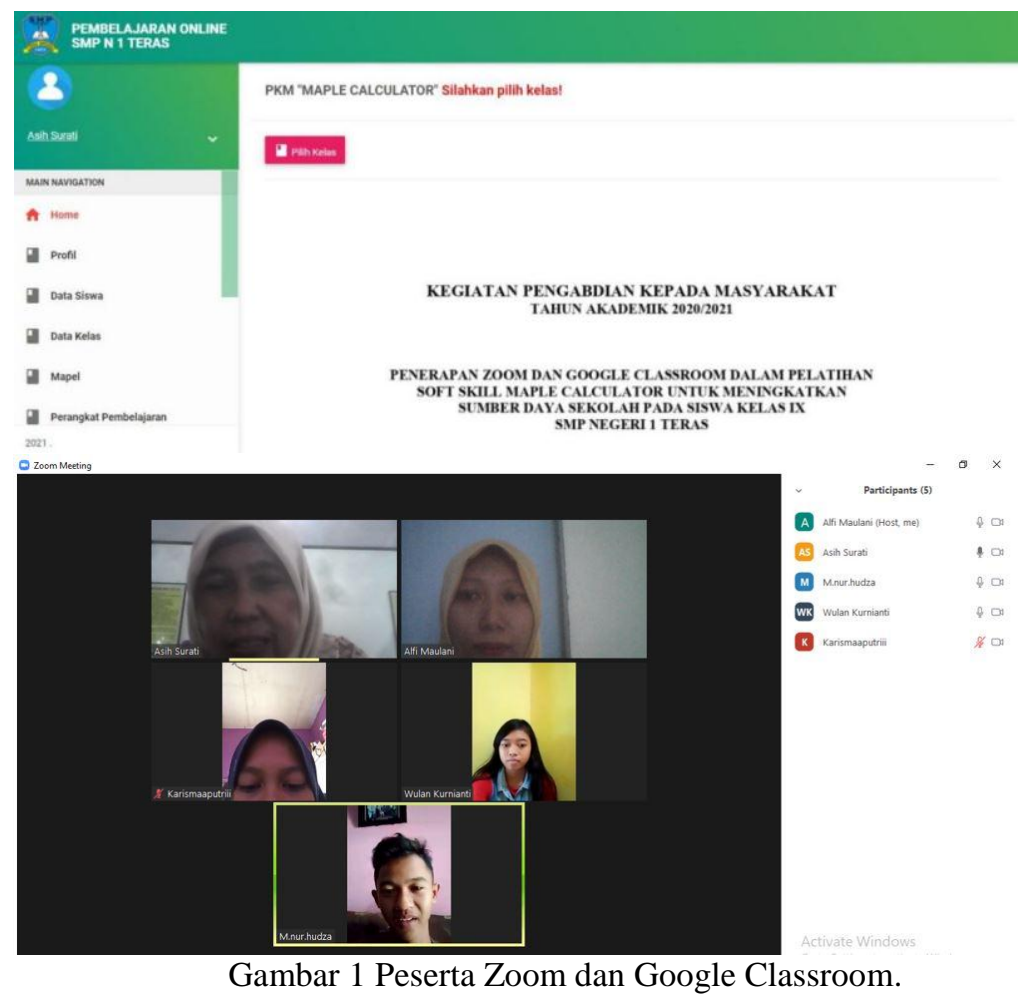

Setelah aplikasi Zoom dan Google Classroom terpasang pada gawai peserta pelatihan yaitu siswa/i kelas IX SMP NEGERI 1 TERAS langkah selanjutnya peserta diundang untuk join dalam kelas PKM Unpam - SMP NEGERI 1 TERAS melalui link undangan:https://us04web.zoom.us/j/5643986313?pwd=R3RJbkZmNVV6ZmpuV1dlS C8zaW13QT09.

Link undangan tersebut selanjutnya disampaikan ke Pihak sekolah SMP NEGERI 1 TERAS yaitu Ibu Sri Supanti Nur Hayati, M.Pd., selaku Kepala Sekolah SMP NEGERI 1 TERAS. Oleh pihak sekolah link tersebut disebarluaskan kepada siswa/i kelas IX SMP 
NEGERI 1 TERAS pada waktu yang telah disepakati, yaitu Selasa, 08 Desember 2020 pukul 09.30 WIB. Tercatat 30 peserta bergabung ke dalam Zoom dan Google Classroom.
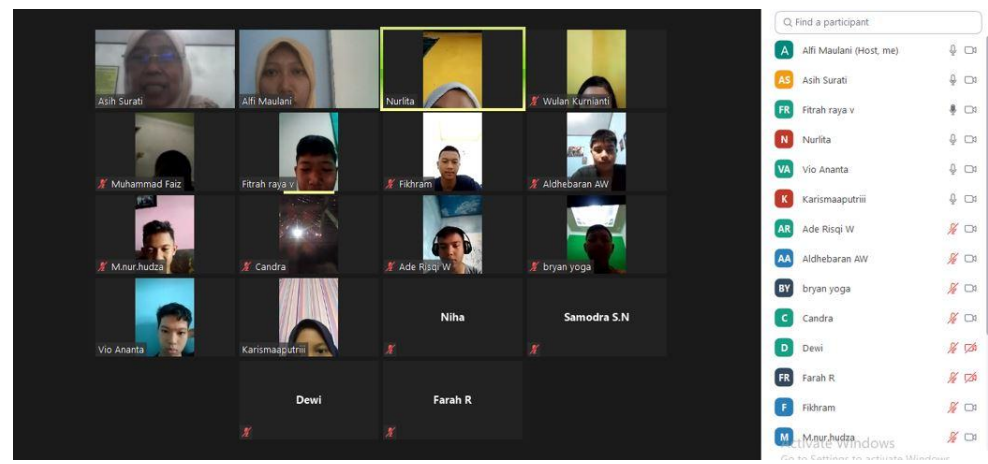

Gambar 2 Sejumlah nama siswa/i kelas IX SMP NEGERI 1 TERAS yang telah join kelas maya Zoom dan Google Classroom.

Tim PKM membuat tugas kelas yang berisi unggahan link materi dan bank soal pelatihan softskill Maple Calculator ke dalam kelas maya Google Classroom sebagaimana tampak dalam Gambar 3.

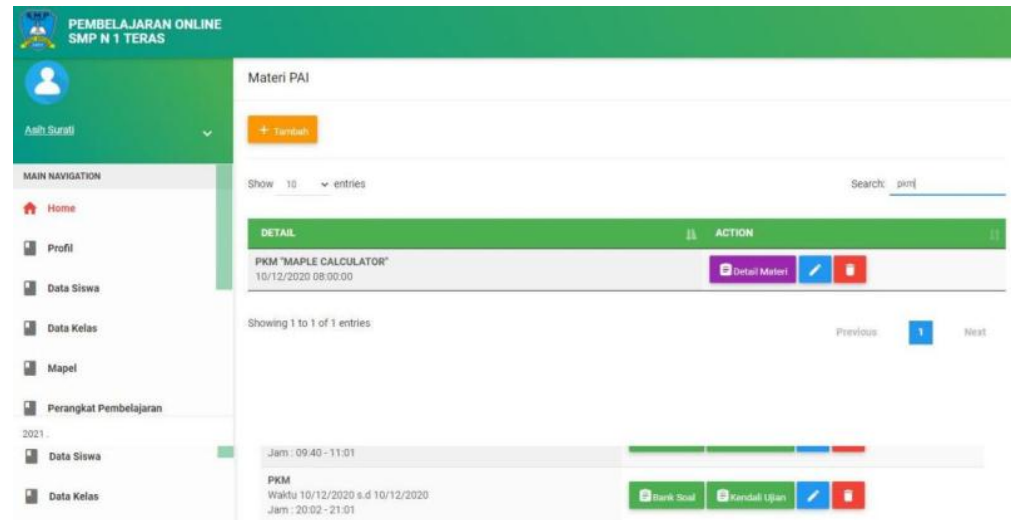

Gambar 3 Tugas kelas yang berisi unggahan link materi dan bank soal pelatihan softskill Maple Calculator.

Isi tugas untuk siswa/i dapat dilihat dengan menekan tombol "Detail Materi" dan "Bank Soal" pada bagian akhir instruksi tertulis. Gambar 4 memperlihatkan isi tugas setelah tombol "Detail Materi" dan "Bank Soal" ditekan atau di-klik.

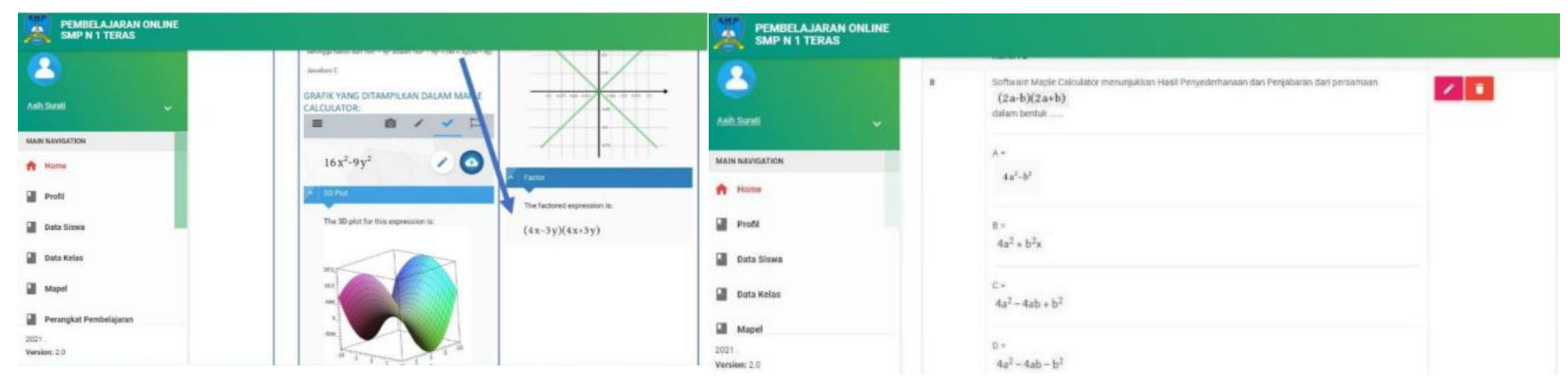

Gambar 4 Beberapa Materi dan Soal pelatihan softskill Maple Calculator dalam Tugas Kelas. 
Beberapa poin dasar dalam tugas kelas adalah :

1). Instruksi tertulis mengenai susunan acara pelatihan.

2). Materi pelatihan Maple Calculator.

3). Bank soal pelatihan Maple Calculator.

4). Absensi Siswa/i berisi isian daftar hadir dan pertanyaan kuesioner.

Diharapkan dengan adanya kegiatan pengabdian kepada masyarakat ini peserta pelatihan memperoleh manfaat berupa:

1). Tambahan dan peningkatan pengetahuan siswa/i kelas IX SMP NEGERI 1 TERAS tentang software Maple Calculator.

2). Peningkatan kesadaran siswa/i kelas IX SMP NEGERI 1 TERAS mengenai bertapa pentingnya software Maple Calculator dalam pendidikan.

3). Peningkatan ketrampilan dan kreativitas siswa/i kelas IX SMP NEGERI 1 TERAS.

\section{Pembahasan Materi}

Materi pelatihan softskill Maple Calculator dibagi menjadi dua bagian. Pada bagian pertama peserta diberi materi tentang operasi hitung dan faktorisasi bentuk aljabar.

\section{AMP. PEMBELAJARAN ONLINE \\ OPERASI HITUNG DAN FAKTORISASI BENTUK ALJABAR}

Gambar 6 Pembukaan acara pelatihan dan Materi pelatihan pada bagian satu: operasi hitung dan faktorisasi bentuk aljabar.

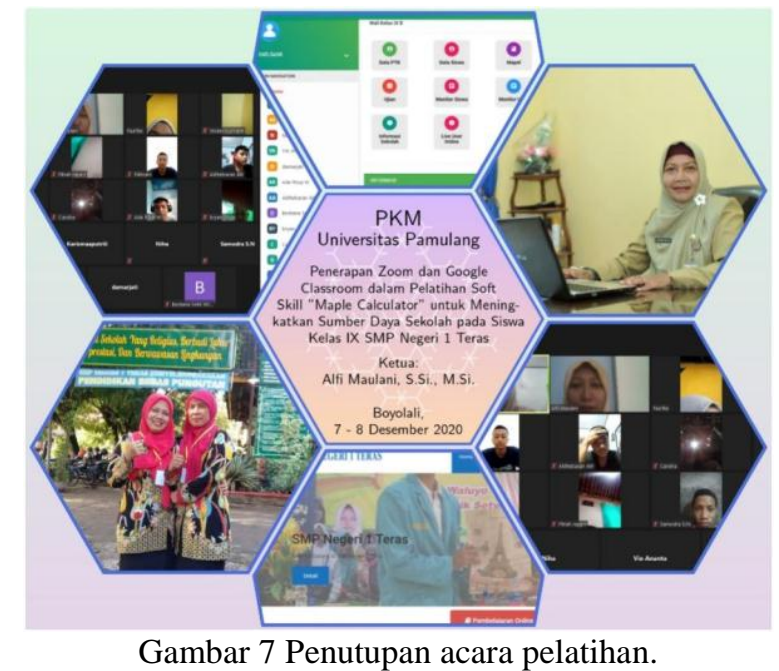

\section{SIMPULAN}

Kegiatan pengabdian kepada masyarakat tentang penerapan zoom dan google classroom dalam pelatihan soft skill Maple Calculator dapat berjalan dengan lancar dan tertib sesuai dengan rencana kegiatan yang sudah disusun sebelumnya. Kegiatan pelatihan ini mendapat sambutan yang baik dari pihak sekolah SMP NEGERI 1 TERAS dan siswa/i Kelas IX. Keseluruhan hasil pelaksanaan pelatihan menunjukan hasil yang baik. Kesimpulan dari adanya pengabdian kepada masyarakat ini antara lain: 
1). Memberikan pengetahuan dalam informasi penggunaan software Maple Calculator, kepada siswa/i kelas IX SMP NEGERI 1 TERAS, Boyolali.

2). Memberikan cara atau metode pelatihan dalam penggunaan software Maple Calculator dan prosedur didalamnya melalui 10 contoh soal dan pembahasan mengenai operasi hitung dan faktorisasi bentuk aljabar dan pencarian Grafik 2D dan 3D dari persamaan tersebut.

\section{DAFTAR PUSTAKA}

Munandar, U. (2014). Pengembangan Kreativitas Anak Berbakat. Jakarta: Rineka Cipta.

Nurina, L. A. (2014). Penerapan Strategi Everyone in a Teacher Here untuk Meningkatkan Kemampuan Pemahaman Matematis dan Kemandirian Belajar Siswa SMP. Bandung: UPI.

Saparwadi, L., \& Yuwono, T. (2019). Pembelajaran Kalkulus Berbantuan Sofware Maple: Studi Perbedaan Hasil Kerja Mahasiswa dengan Menggunakan Maple dan Tanpa Menggunakan Maple. Jurnal Elemen, Vol.5 , No.1, 23-30.

Suhandri, \& Senada. (2016). Implementasi Program Aplikasi Maple untuk Meningkatkan Prestasi dan Motivasi Belajar Mahasiswa pada Perkuliahan Kalkulus Integral. Suska Journal of Mathematics Education, Vol-2, No.1, 57-66. 